Journal of Aquatic Animal Health 10:264-270, 1998 (C) Copyright by the American Fisheries Society 1998

\title{
Eimeria southwelli Infection Associated with High Mortality of Cownose Rays
}

\author{
M. Andrew Stamper*1 And Gregory A. Lewbart \\ Environmental Medicine Consortium, North Carolina State University and \\ Department of Companion Animal and Special Species Medicine \\ College of Veterinary Medicine, North Carolina State University \\ 4700 Hillsborough Street, Raleigh, North Carolina 27606, USA \\ PAUL R. BARRINGTON \\ North Carolina Aquarium, Fort Fisher \\ 2201 Fort Fisher Boulevard, South, Box 1, Kure Beach, North Carolina 28449, USA
}

\section{Craig A. Harms}

Environmental Medicine Consortium, North Carolina State University and Department of Microbiology, Physiology, and Pathology

College of Veterinary Medicine, North Carolina State University

\section{FRANK GEOLY²}

Environmental Medicine Consortium and Department of Microbiology, Physiology, and Pathology College of Veterinary Medicine, North Carolina State University

\section{Michael K. Stoskopf}

Environmental Medicine Consortium, North Carolina State University and Department of Companion Animal and Special Species Medicine College of Veterinary Medicine, North Carolina State University

\begin{abstract}
The coccidian Eimeria southwelli is associated with chronic fatal disease in captive cownose rays Rhinoptera bonasus. Clinical signs include discoloration of the epidermis, emaciation, coelomic cavity distention, and death. The oocysts can be demonstrated in coelomic fluid obtained by coelomic aspiration. Prevalence of E. southwelli in wild cownose rays was $92 \%$ in Pamlico Sound, North Carolina, USA. Recommended management practices include strict quarantine and screening by using coelomic cavity aspirate sampling. A dosage of $10 \mathrm{mg}$ toltrazuril $/ \mathrm{kg}$ orally once a day for $5 \mathrm{~d}$ reduces but may not eliminate parasitic loads.
\end{abstract}

Eimeria southwelli (coccidia) was first described in spotted eagle rays Aetobatus narinari in 1930 (Halawani 1930) and was later implicated as a possible cause of mortality in cownose rays Rhinoptera bonasus (Cheung 1993). This paper describes clinical manifestations of fatal disease associated with $E i$ meria southwelli in cownose rays housed during a 5year period at an exhibit aquarium in North Carolina. The epidemiology and control of the disease in mixed-species, closed recirculating water systems is discussed based on the results of a retrospective epidemiological study of captive rays, a survey of wild

\footnotetext{
* Corresponding author.

1 Present address: New England Aquarium, Central Wharf, Boston, Massachusetts 02110-3399, USA.

2 Present address: Heska Corp., 1825 Sharp Point Drive, Fort Collins, Colorado 80525, USA.
}

rays, and a clinical investigation of infected captive rays that included therapeutic trials.

\section{Methods}

Retrospective epidemiology study of captive animals.-A review of the records for the 5 years prior to initiation of the clinical investigation established the numbers and timing of wild cownose ray acquisition, morbidity, and duration of signs in diseased rays and allowed for calculation of mortality rates. It also established interspecies contact histories, captive diet history, treatments, and patterns of environmental parameters. A retrospective analysis of pathology reports for 24 cownose rays that died during the 5 -year period was also performed.

Clinical investigation.-The 18-month clinical prospective study included 13 cownose rays. 
These rays were separate from the retrospective study but were held in the same tanks and conditions.

Clinical examination included direct visualization of the gills, mouth, cloaca, and external body. The animals were weighed out of water. Attempts were made to collect fecal samples with cottontipped applicator sticks (Puritan, Hardwood Products Co., Guildford, Massachusetts, USA) through an otoscope (Welch Allyn, Inc., Scaneateles Falls, New York, USA) inserted into the cloaca. This was successful in only 4 of the 13 animals. Fecal samples were successfully obtained from the other nine rays by using a colonic flush technique. A 4mm urinary catheter (Sovereign, Sherwood Medical, Saint Louis, Missouri, USA) attached to a 6$\mathrm{mL}$ syringe was used to catheterize the colon, and $5 \mathrm{~mL}$ of $0.9 \%$ saline (Baxter Healthcare Products, Deerfield, Illinois, USA) were infused, then aspirated, to obtain the sample. Fecal samples were examined under $200 \times$ and $400 \times$ magnification by direct visualization of a wet smear and after fecal flotation, by using a saturated solution of sodium nitrate (Fecasol, Evsco Pharmaceuticals, Beuna, New Jersey, USA).

Coelomic cavity sampling was performed on all elasmobranchs in the tank including cownose rays, clearnose skates Raja eglanteria, yellow stingrays Urolophus jamaicensis, Atlantic stingrays Dasyatis sabina, southern stingrays Dasyatis americana, and bluntnose stingrays Dasyatis say. Aspirates were obtained by using a 21-gauge, 19-mm winged infusion set (Surflo, Terumo Medical Corp., Elkton, Maryland, USA) attached to a $12-\mathrm{mL}$ syringe. Rays were placed on a precut section of opencelled foam designed to permit caudoventral body wall dependency and coelomic fluid pooling at the sampling site. The infusion set needle was inserted parallel to the skin through the right ventral paramedian body wall just cranial to the pelvic girdle and with the bevel facing the center of the coelomic cavity. In this location the spiral colon is in contact with the peritoneal serosa, minimizing the chances of perforating the liver. When a sample could not be obtained with this method, sterile $0.9 \%$ saline, at a dose of $1 \%$ of the animal's body weight, was infused into the coelomic cavity and aspirated.

Gross postmortem examinations were performed on all species of fishes that died in display tanks or in quarantine cownose ray tanks during the study period. The presence of gross lesions or coccidia were noted for all fishes. Coelomic fluid samples as well as intestinal and endometrial mu- cosal smears of all rays were examined under $200 \times$ and $400 \times$ magnification. In a subset of four representative infected cownose rays, bacterial culture samples were obtained from blood or kidneys, and tissue samples were taken from the skin, gills, skeletal muscle, brain, heart, liver, spleen, pancreas, intestine, kidney, uterus-ovary or testis, and rectal gland. These were placed in $10 \%$ buffered formalin (Fisher Chemical, Fair Lawn, New Jersey, USA) for histopathological examination. Tissues were routinely processed in paraffin, sectioned, and stained with haematoxylin and eosin (Conn 1961).

Anatomical features of the coccidia obtained with aspirates were reviewed at $400 \times$ and $1,000 \times$ magnification, and morphological features including oocyst size and sporocyst and sporozoite numbers and sizes were compared with the description of E. southwelli oocysts (Cheung 1993) and verified by using the original description (Halawani 1930). Spores and oocysts were fixed for electron microscopy by using a variety of fixation protocols including Davidson's solution, Trump's liquid, 2\% glutaraldehyde, and $2 \%$ glutaraldehyde in seawater (McDowell and Trump 1976; Humason 1979). Prepared samples were viewed with a Philips 410LS transmission electron microscope.

Survey of wild rays. - A cohort of 37 wild cownose rays collected as bycatch from a pound-net fishery located in Pamlico Sound, North Carolina $\left(N=21\right.$ from $35^{\circ} 02.41^{\prime} \mathrm{N}, 76^{\circ} 07.13^{\prime} \mathrm{W} ; N=10$ from $34^{\circ} 58.8^{\prime} \mathrm{N}, 76^{\circ} 12.9^{\prime} \mathrm{W}$; and $N=6$ from $34^{\circ} 56.03^{\prime} \mathrm{N}, 76^{\circ} 15.95^{\prime} \mathrm{W}$ ) was examined to establish the prevalence of the disease in the wild. Within $30 \mathrm{~min}$ of death, coelomic fluid samples were obtained with the previously described coelomic aspiration techniques. Wet smears of these fluids were examined at $200 \times$ and $400 \times$ magnification. After the coelomic cavities were aspirated, necropsies were performed and tissue samples of spiral colon, pancreas, peritoneal lining, and liver were collected and stored in $10 \%$ buffered formalin. Histopathological examination was performed on rays deemed negative by examination of the coelomic aspirates.

Environmental sampling.-To find the organism in the system environment, five $100-\mathrm{mL}$ water column samples and five $50-\mathrm{mL}$ samples from the foam fractionater were centrifuged at $140 \times$ gravity, $g$, for $5 \mathrm{~min}$ and the pellets were collected. Ten- $\mu \mathrm{m}$ filter bags (Micron Bags, Aquaculture Supply, Division of Florida Aqua Farm, Inc., Dade City, Florida, USA) were placed in the tank's outflow for $12 \mathrm{~h}$ on three separate occasions. Thirty- 
seven liters of tank water were filtered per minute. Wet smears of the filtrate were examined at $200 \times$ magnification. Analysis of the tank's substrate was performed on samples obtained from five regions of the tank. One hundred $\mathrm{mL}$ of gravel substrate were taken at the substrate surface and at a depth of $15 \mathrm{~cm}$ in the substrate at each sampling point. These substrate samples were washed over a 800 $\times 400-\mu m$ nylon mesh (Economy Aquarium Nets, Aquaculture Supply) with $100 \mathrm{~mL}$ of tank water. These washes were centrifuged at $140 \times g$ for 5 min and the pellets were collected. Wet smears of the pellets were examined at $200 \times$ magnification.

Three 100-g samples of frozen shrimp, fish, squid, and clams, collected 3 months apart, were macerated. Five-mL aliquots of each sample were placed in a saturated solution of sodium nitrate to concentrate oocysts, which were examined under $200 \times$ magnification.

Stability of organism.-In vitro storage of the organisms obtained from coelomic aspirations was performed to determine environmental stability. Oocysts were placed in silicon-coated glass tubes (Becton Dickinson and Co., Rutherford, New Jersey, USA) containing $3 \mathrm{~mL}$ of artificial seawater (32 g Instant Ocean/L; Aquarium Systems, Mentor, Ohio, USA); they were examined under $200 \times$ and $400 \times$ magnification at 1 and 2 weeks, 1, 3, 6 and 8 months, and 1 year. Subsets of organisms were frozen in artificial seawater (32\%o) or $0.9 \%$ saline, stored at $-20^{\circ} \mathrm{C}$ for 1 week, and then thawed at room temperature for examination.

In vivo drug application.-Three infected rays showing clinical signs were anesthetized in a bath of tricaine methanesulfonate (Finquel, Argent, Redmond, Washington, USA) at $250 \mathrm{mg} / \mathrm{L}$ and gavaged once with toltrazuril at the recommended dose for chickens: $25 \mathrm{mg} / \mathrm{kg}$ (Laczay et al. 1995). This dose was reduced to $10 \mathrm{mg} / \mathrm{kg}$ daily for $5 \mathrm{~d}$ with toltrazuril diluted 50:50 (volume: volume) with tap water $(12.5 \mathrm{mg} / \mathrm{mL})$. One animal died 3 $\mathrm{d}$ after the completion of treatment and was necropsied. Coelomic samples were obtained from the other two rays 4 and 11 months after treatment. To further reduce the dose and dosing frequency, a dose of $10 \mathrm{mg} / \mathrm{kg}$ given every other day for three treatments was attempted in four additional positive rays.

\section{Results \\ Retrospective Epidemiology Study}

Twenty-four immature cownose rays were housed for various lengths of time in a 40,000-L mixed-species recirculating water system during the 5-year period covered by the retrospective epidemiologic study. Twenty-one of those cownose rays originated from wild sources along the Atlantic coast and the other three were acquired from two aquaria. Other species housed in the system were sandbar sharks Carcharhinus plumbeus, Atlantic sharpnose sharks Rhizoprionodon terraenovae, bullnose rays Myliobatis freminvillei, clearnose skates, yellow stingrays, Atlantic stingrays, southern stingrays, bluntnose stingrays, common snook Centropomus undecimalis, ladyfish Elops saurus, lookdowns Selene vomer, Atlantic silversides Menidia menidia, Atlantic bumpers Chloroscombrus chrysurus, and horseshoe crabs Limulus polyphemus. Food items provided included shrimp, clams, and squid along with locally purchased whole fish. All food items were frozen to $-30^{\circ} \mathrm{C}$ for at least 2 weeks prior to feeding.

Clinical disease in cownose rays was reported between 1 and 6 months after introduction into the exhibit. Initial signs were distended cutaneous lymphatics and epidermal pallor. As the disease progressed, coelomic cavity distention became more evident. Body condition deteriorated despite normal appetite, and the rays became emaciated. Approximately 1 week prior to death, the pale epidermis changed to a dark mottled pattern and the fish began to swim erratically. The rays became anorexic $12-24 \mathrm{~h}$ prior to death. Oral treatment with $10 \mathrm{mg}$ trimethoprim-sulfadimethoxine $/ \mathrm{kg} \mathrm{ev-}$ ery other day for $14 \mathrm{~d}$ was unsuccessful. Postmortem reports revealed that dead animals included 24 cownose rays, 2 bullnose rays, 2 clearnose skates, a yellow stingray, and an Atlantic stingray. Prevalence of infection with coccidia in the cownose ray population was $100 \%$. Necropsy records indicated Eimeria or Eimeria-like organisms in the coelomic cavities of two bullnose rays and two clearnose skates; however, these organisms were not identified specifically at the time of necropsy. No coccidia-like organisms were reported in the yellow stingray or the Atlantic stingray.

\section{Clinical Investigation}

Antemortem coelomic fluid samples of the 13 cownose rays (6 males and 7 females) housed in the exhibit during the 18-month prospective study showed a $100 \%$ prevalence of infection with coccidia. Body weights ranged from 1.25 to $2.16 \mathrm{~kg}$ (males $1.25-2.16 \mathrm{~kg}$, females $1.6-2.05 \mathrm{~kg}$ ). During the 18-month study cownose rays were housed with bonnetheads Sphyrna tiburo $(\mathrm{n}=2)$, bullnose rays $(n=3)$, clearnose skates $(n=6)$, yellow 


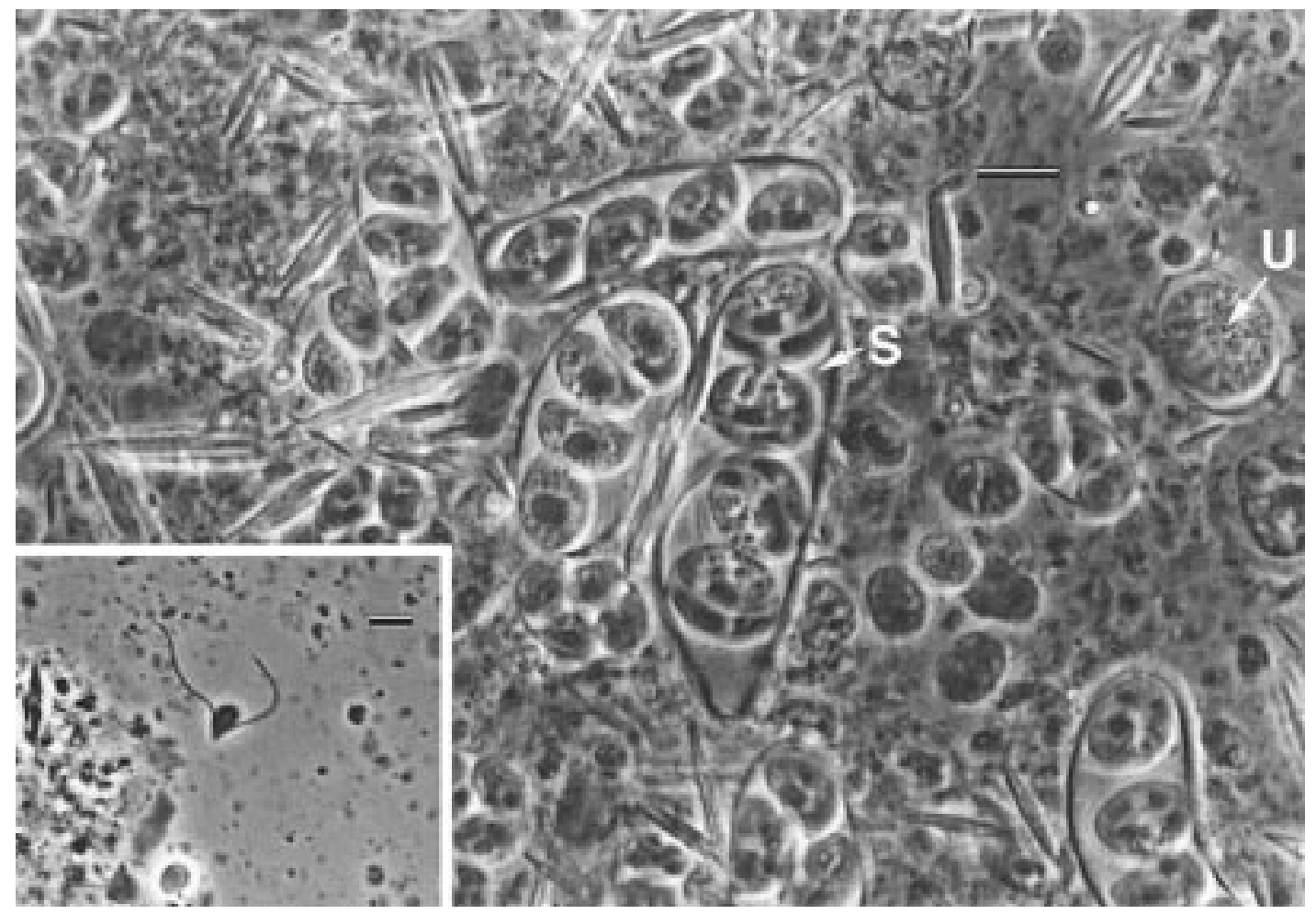

FigURE 1.-Sporulated (S) and unsporulated (U) Eimeria southwelli oocysts in coelomic fluid of cownose ray (bar $=10 \mu \mathrm{m})$; inset: biflagellated microgamete $(\mathrm{bar}=5 \mu \mathrm{m})$.

stingrays $(n=4)$, Atlantic stingrays $(n=4)$, southern stingrays $(n=3)$, bluntnose stingrays $(n=2)$, and common snook $(n=2)$. The dietary management for these animals was the same as described above. Similar clinical disease was seen as reported in the historical reports and became evident between 1 and 6 months after introduction of cownose rays into the exhibit. Eleven of the 13 rays eventually died.

Postmortem samples of 11 cownose rays confirmed the presence of oocysts. Infections were determined by finding opaque white-to-tan coelomic fluid containing polymorphic oocysts and motile biflagellated 3-4- $\mu \mathrm{m}$ microgametes (Figure 1). Oocysts were not demonstrated on direct fecal or fecal wash samples.

Necropsy findings included serous, semitransparent, white-to-tan-to-pink effusion filling the coelomic cavity, generalized serositis, and cutaneous lymphangiectasia. Coccidial oocysts in various stages of development were readily demonstrated in the coelomic cavity effusion by cytologic examination, but no oocysts were found in the feces or mucosal smears of the intestines. Histopathological examination of the serosal surfaces of the ovary, liver, pancreas, kidney, and spleen showed multifocal mesothelial proliferation 2-3 cell layers deep with mild-to-moderate mononuclear inflammatory cell infiltrates. Within these serosal surfaces, sporulated and unsporulated oocysts as well as rare meronts were intermixed within the inflammatory infiltrate. Examination of other tissues did not show pathological lesions or coccidia life stages. No bacteria grew on aerobic cultures from two of the cownose rays. A mixed infection of Vibrio alginolyticus and Streptococcus spp. was found in one ray, and Citrobacter amalonaticus and two Enterobacter species were found in the other. Necropsies on other animals that died during various times throughout the 18-month period (three bullnose rays, four clearnose skates, two yellow stingrays, two Atlantic stingrays, and a bluntnose stingray) did not show patterns of mortality or lesions consistent with coccidial infections.

\section{Survey of Wild Rays}

The prevalence of Eimeria southwelli in the wild population sampled in Pamlico Sound, North Carolina, was $92 \%$ (34/37). Thirty-one of 37 animals 
were positive for E. southwelli based on examination of coelomic washes. Aspirate samples without saline flushes were successfully obtained from 8 of 37 animals. With these samples, $0.2-0.7 \mathrm{~mL}$ of fluid was aspirated from the coelomic cavity. Samples collected with sterile $0.9 \%$ saline harvested between 0.2 and $3.0 \mathrm{~mL}$ of fluid. Between the two techniques, samples were obtained from 37 of 37 animals. Of the six rays in which coccidia were not demonstrated, with the aspirate technique, three were positive on histopathological examination. Inflammation was not associated with the infections. Serositis was present in the fourth animal but no organisms were found. Neither organisms nor inflammation were demonstrated in the remaining two animals.

Sporulated and unsporulated coccidial oocysts were polymorphic, ranging between 15 and $63 \mu \mathrm{m}$ in length and 10 and $15 \mu \mathrm{m}$ in width. The oocyst wall was $2 \mu \mathrm{m}$ thick with a micropyle located at one end of the oocyst. Sporocysts were 10-12 $\mu \mathrm{m}$ long with sporozoites ranging from 5 to $10 \mu \mathrm{m}$ long and $2 \mu \mathrm{m}$ wide. Mature sporocysts were pearshaped with a ridge-like structure along the length. A polar Stieda body was evident on the end of the sporocysts. Morphology and the cownose ray host are consistent with Eimeria southwelli (Halawani 1930; Cheung 1993). Inadequate fixative penetration of the oocyst wall hampered interpretation of ultrastructural morphology.

\section{Environmental Sampling}

Oocysts were not found in water, sediment, foam fractionater byproducts, or food items. No oocysts were found in coelomic samples of other elasmobranchs present in the tank at the time of the prospective study.

\section{Stability of Organisms}

Eimeria southwelli organisms held in seawater at $21^{\circ} \mathrm{C}$ maintained structural integrity after 2 years of storage. Morphological structure was disrupted by 1 week of freezing at $-20^{\circ} \mathrm{C}$ in either artificial seawater $(32 \%$ ) or $0.9 \%$ saline.

\section{Drug Efficacy}

Two of 3 critically moribund cownose rays treated with $10 \mathrm{mg}$ toltrazuril/kg by gavage for $5 \mathrm{~d}$ regained normal coloration and condition within 2 weeks of treatment and remained asymptomatic at least 11 months after treatment. No oocysts or microgametes could be demonstrated by coelomic aspiration when the rays were tested at 4 and 6 months, but samples from asymptomatic animals taken 11 months after treatment were positive. Histological examination of the third ray, which died $3 \mathrm{~d}$ after toltrazuril treatment, showed the presence of oocysts in the coelomic cavity but no meronts in the serosal mesothelium. Four more infected positive rays were treated with a dose of $10 \mathrm{mg}$ / $\mathrm{kg}$ given every other day for three treatments but this was determined to be ineffective.

\section{Discussion}

Systemic coccidiosis with Eimeria southwelli can be lethal in cownose rays. In this collection all of the rays were infected, and they died if they were not treated. Prominent clinical signs of the E. southwelli infection included distended cutaneous lymphatics, epidermal pallor, and deteriorating body condition. Coelomic cavity distention with a white-to-pink, flocculant, coelomic effusion was consistently observed in all rays that died. Oocysts were found in large numbers (multiple organisms in every $200 \times$ magnification field) in coelomic fluid of all deceased rays. Histopathological evaluation demonstrated rare meronts replicating in the serosal tissue of the intestines, pancreas, peritoneal lining, and liver. Evaluation of the parenchyma of these tissues, as well as other tissues such as the heart, kidney, skeletal muscle, gills, and brain, did not demonstrate other intracellular or extracellular coccidial stages. Although other potential pathogens were isolated from individual animals with coccidia, there was no evidence that concomitant infections with other pathogens caused mortality. Other animals that died in the system had no pattern of infectious diseases and did not show evidence of coccidial infections.

Oocysts had morphologic features resembling those of Eimeria southwelli, which is described as having polymorphic oocysts with lengths ranging from 15 to $50 \mu \mathrm{m}$ and widths between 10 and 12 $\mu \mathrm{m}$ (Halawani 1930; Cheung 1993). Sporocysts and sporozoites of $E$. southwelli ranged between 10 and $12 \mu \mathrm{m}$ in length. Morphological features including the location of a micropyle at one end of the oocyst, the presence of a ridge along the sporocyst wall, as well as a Steida body located at one end of the sporocyst, assisted with identification. The original description did not characterize a true micropyle but described an immature oocyst with a small narrowing of the oocystic wall, which appeared to indicate its position at one end (Halawani 1930). In this study, as well as in Cheung's (1993), a more distinct micropyle was present. It is uncertain whether there was a dif- 
ference in observational technique or development of the coccidia between these studies.

In this study the electron microscopy fixatives used were not effective in oocyst preservation. Future electron microscopy studies may benefit by using urea and sodium chloride balanced fixatives, which match the internal osmotic physiological parameters of elasmobranchs (Stoskopf 1993).

Endometrial infections have been previously described (Cheung 1993), and endometrial sloughing could be one route for environmental contamination. No oocysts were demonstrated in the intestinal tract, renal tissue, or uterus in our study, and we have no direct evidence that cownose rays act as direct sources of infection for other animals. Release of oocysts through the death and decomposition of host tissues is another possible mode of transmission particularly in the wild, but all animals in our captive studies were removed prior to decomposition. If this were a major route of dissemination of the organism into the environment, it could help explain our failure to detect organisms through environmental sampling of the exhibit.

Direct transmission through environmental contamination is possible. Although no infectivity trials could be conducted because of our inability to obtain uninfected rays, in vitro oocysts stored in seawater maintained morphological stability for more than 2 years.

A $92 \%$ prevalence of coccidiosis in wild cownose rays at the collection site suggests the majority of rays were infected prior to entry into the exhibit. Cownose rays from other collections could have been harboring the organism prior to entry, even though they were not showing clinical evidence of the disease. Asymptomatic infections were detected in wild rays as well as in rays caught and placed in quarantine. We speculate that infections could have become pathogenic due to stressors in the captive environment. Otherwise, if the extremely high morbidity and mortality observed in the captive animals was normal for wild animals, this would have a devastating effect on population dynamics.

Other species exhibited in the tank were sampled as we looked for evidence of an indirect life cycle or that cownose rays could be an aberrant host. Historical tank records listed coccidiosis in the bullnose rays and clearnose skates, but the organisms were not identified. Our literature search showed spotted eagle rays have been demonstrated to harbor Eimeria species (Halawani 1930; Boulard 1977), but we did not uncover reports of coc- cidial infections affecting bullnose rays or clearnose skates. Coelomic aspirates and fecal analysis were performed on all fishes exhibited at the time of the clinical investigation except for common snook, which avoided capture. All ray species were negative with these sampling methods.

Oocyst introduction through the food appears to be unlikely. No oocysts were found in macerated food samples, possibly because the oocysts do not infect these species of animals or our sampling size was inadequate. Freezing at $-20^{\circ} \mathrm{C}$ for 1 week disrupted the morphological structure of the oocysts, and all food was frozen at $-30^{\circ} \mathrm{C}$ for at least 2 weeks before being fed. It is possible that oocysts, surrounded by tissue, may be cryoprotected.

Control of the disease has been difficult. Identification of infected rays prior to clinical disease is an important component of controlling the disease in captivity. With a sensitivity slightly more than $90 \%$, antemortem coelomic aspirates are an effective tool to screen for $E$. southwelli infections. False negatives with this assay were animals with few or no histologic lesions.

Toltrazuril appears to be effective against this species of coccidium. Regurgitation and intestinal hypermobility induced by $25 \mathrm{mg} / \mathrm{kg}$ dosage indicated the need to deliver it in a more dilute formulation. The dose of $10 \mathrm{mg} / \mathrm{kg}$ given orally once daily for $5 \mathrm{~d}$ alleviated clinical signs in two rays for 11 months. Alternate day delivery was ineffective. It is uncertain whether the treatments eradicated the coccidia and the treated rays later became reinfected or if the population of coccidia was reduced to below the sensitivity of the coelomic aspirate sampling technique.

Systemic coccidiosis in cownose rays is likely to be a large problem in public display aquaria; it is often misdiagnosed as chronic wasting from maladaption. Until geographic distribution of the disease is established and unaffected rays located, all aquaria should institute quarantine with diagnostic testing to eliminate infected rays from entering display tanks.

\section{Acknowledgments}

We thank Andrea Wrangell and Joe Spitzer from the North Carolina Aquarium at Fort Fisher as well as Pam Dennis and Karen Beck from North Carolina State College University of Veterinary Medicine for their assistance with this study. We also appreciate Michael Dykstra and Frank Perkins from North Carolina State College University of Veterinary Medicine for assisting us with the elec- 
tron microscopy sample processing and interpretation.

\section{References}

Boulard, Y. 1977. Descriptio d'eimeria auentini n. sp., parasite intranucléaire du péritoine de la raie: $a e$ tobatis narinari (Chondrichthyes, Myoliobatidae) en malaisie. Protistologica 8:529-533.

Cheung, P. 1993. Eimeria southwelli, 1930 (Apicomplexa: Coccidia) from a new host, the cownose ray, Rhinopterus bonasus Mitchill. Journal of Aquariculture and Aquatic Sciences 32:293-365.

Conn, H. J. 1961. Biological stains. 7th edition. Biochemical Publications, New York.

Halawani, A. 1930. On a new species of eimeria (E. southwelli) from Aetobatis narinari. Annals of Tropical Medicine and Parasitology 24:1-3.

Humason, G. L. 1979. Animal tissue techniques. Freeman, San Francisco.
Laczay, P., G. Vörös, and G. Semjén. 1995. Comparative studies on the efficacy of sulfachlorpyrazine and toltrazuril for the treatment of caecal coccidiosis in chickens. International Journal for Parasitology 25:752-756.

Marshall, R. 1993. Avian anthelmintics and antiprotozoals. Pages 33-41 in A. Fudge, editor. Seminars in avian and exotic pet medicine, volume 2. Saunders, Philadelphia.

McDowell, E. M., and B. F. Trump. 1976. Histological fixatives suitable for diagnostic light and electron microscopy. Archives of Pathology and Laboratory Medicine 100:405-414

Stoskopf, M. K. 1993. Shark pharmacology and toxicology. Pages 809-816 in M. Stoskopf, editor. Fish medicine. Saunders, Philadelphia.

Received December 5, 1997 Accepted March 10, 1998 